\title{
Expression of the "glanded-plant and glandless-seed" trait of Australian diploid cottons in different genetic backgrounds
}

\author{
${ }^{\mathrm{a}}$ Halima Benbouza , ${ }^{\mathrm{b}}$ George Lognay, ${ }^{\mathrm{c}}$ Jodi Scheffler, ${ }^{\mathrm{a}}$ Jean Pierre Baudoin, ${ }^{\mathrm{a}}$ Guy Mergeai \\ ${ }^{a}$ Department of Tropical Crop Husbandry and Horticulture, Gembloux Agricultural University, Passage des Déportés 2, 5030 Gembloux, \\ Belgium \\ ${ }^{b}$ Department of Analytical Chemistry, Gembloux Agricultural University, Passage des Déportés 2, 5030 Gembloux, Belgium \\ ${ }^{c}$ USDA-ARS, 141 Experiment Station Road, Stoneville, MS 38776, USA
}

\begin{abstract}
The expression of the "glanded-plant and glandless-seed" trait was assessed using High Performance Liquid Chromatography (HPLC) analysis methods in different Gossypium hybrids obtained by crossing Australian diploid cottons and various diploid and tetraploid species. Significant variation in the gossypol content in the seed was observed among the analyzed genotypes. HPLC data demonstrated that the gossypol synthesis repression mechanism in the Australian diploid species belonging to $\mathrm{C}$ and $\mathrm{G}$ genomes was dominant but did not confirm its preferential functioning against A genome species bearing $\mathrm{GL}_{2}$ locus. About $10 \%$ of the produced seeds had total gossypol content lower than the limit imposed by the World Health Organisation (600 ppm) for the use of cotton flour in food and feed. HPLC analysis of the terpenoids aldehyde (TA) contents in the aerial parts of the hybrids showed important qualitative and quantitative variability. This result could indicate a certain separation between pigment gland morphogenesis and terpenoid synthesis mechanisms in cotton.
\end{abstract}

Keywords: Gossypium · Introgression · Interspecifics hybrids $\cdot$ Seed gossypol quantification $\cdot$ Cotton $\cdot$ HPLC

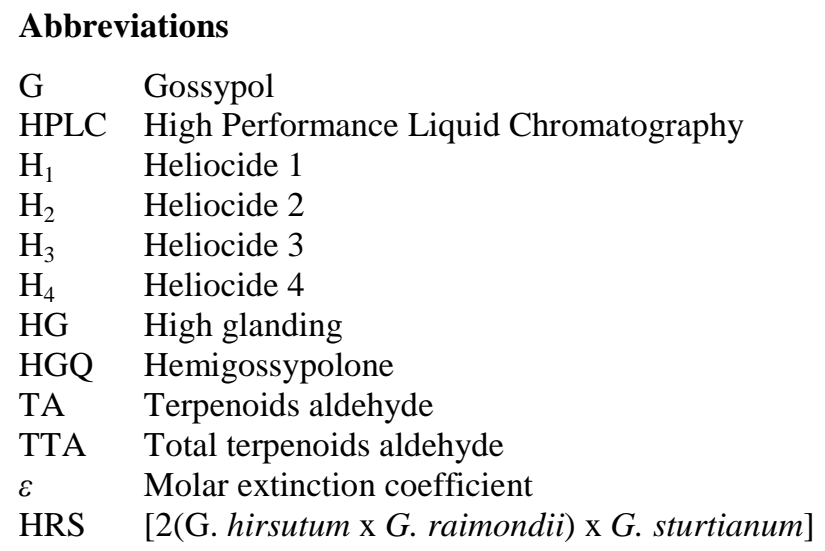

\section{Introduction}

The presence of lysigenous glands filled with gossypol and other terpenoid aldehydes (TA) in most tissues of cultivated cotton induces natural resistance to insect pests (Altman et al. 1990) Most studies regarding the TA composition and content in Gossypium species indicated the existence of differences between foliar and seed TA. High Performance Liquid Chromatography (HPLC) analysis results showed that gossypol is the main TA in seed but not in foliar glands. Hemigossypolone and the heliocides constitute up to $90 \%$ of the total TAs in leaves and up to $45 \%$ in flower buds (Altman et al. 1989; Stipanovic et al. 1988).

The TA content in cotton species (Gossypium spp.) is controlled by at least six independent loci, namely $g l_{l}, g l_{2}$, $g l_{3}, g l_{4}, g l_{5}$ and $g l_{6}$ (Pauly 1979). The formation of gossypol glands in tetraploid upland cotton (G. hirsutum) is controlled by two main alleles $G_{2}$ and $G l_{3}(5)$ and seed glanding is determined mainly by the $G l_{2}$ allele (Lee 
1965; Pauly 1979; McCarty et al. 1996). McMichael (1954) reported two recessive mutant allele's $g l_{2}$ and $g l_{3}$ which completely removed pigment glands from the whole plant, and resulted in nontoxic cottonseed when they were simultaneously present in a recessive homozygous state.

Among the 50 species of Gossypium, the "glandless-seed and glanded-plant" trait is found only in some Australian wild species belonging to Sturtia and Hibiscoidea sections (Brubaker et al. 1996). All the Australian native diploid species belonging to these sections such as G. sturtianum and G. australe present this natural trait which means they produce seed without visible pigment glands but still possess foliar gossypol glands that endow them with a certain level of protection against herbivores. These Australian cottons of $\mathrm{C}$ and $\mathrm{G}$ genomes are however phylogenetically remote from upland cotton. In these plants, the genes involved in gossypol gland formation appear to be controlled by a repressive mechanism which acts until the cotyledons open and the young plantlets begin to synthesize chlorophyll (Fryxell 1965). After the formation of the chlorophyll all aboveground parts of the plant, issued from glandless seed, are glanded. To date, the functioning of this repressive mechanism and its genetic determinism in the Australian wild species remains unknown. Recent works using SSR markers to monitor introgression the "glandless seed and glanded plant" trait in a trispecific hybrid indicated that the trait may be controlled at least by two major genes (Benbouza et al. 2007). The quantification of the "glanded-plant and glandless-seed" trait is generally made either visually (level of glanding) or chemically (quantification of TAs content).

Shuijin and Biling (1993) have evaluated visually the expression of the "glandless-seed and glanded plant" trait on seeds produced by a synthetic allotetraploid obtained by crossing $G$. bickii $(2 n=2 x=26$, genome $\mathrm{G})$ with $G$. arboreum $(2 n=2 x=26$, genome A). The seeds were completely glandless and gave rise to glanded seedlings.

Dilday (1986) identified a fertile allohexaploid $(2 \mathrm{M}=78)$ in Muramoto's original material (Muramoto 1969). This allohexaploid was obtained by an interspecific cross of tetraploid $(2 n=52)$ G. hirsutum x a wild diploid species $G$. sturtianum Willis $(2 n=26)$. The material showed a phenotype having "glandless-seed and glandedfoliage". The glandless phenotype had only $0.02 \%$ seed gossypol. Most of the pentaploids obtained by crossing G. hirsutum with G. sturtianum Willis or G. australe F. von Muller had lower seed gossypol content than the cultivated parent and a normal gossypol concentration in the other parts of the plant (Muramoto 1969; Dilday 1986; Koto 1989).

Altman et al. (1987) obtained $\mathrm{BC}_{4}$ seeds with no gossypol glands using the $2(\mathrm{G}$. hirsutum $\mathrm{x}$ G. sturtianum) hexaploid but the trait was not transmitted to the progeny; this characteristic was also not observed in any of the monosomic alien addition families obtained by crossing G. hirsutum with Australian species (Koto 1989; Rooney et al. 1991; Ahoton et al. 2003).

Vroh Bi et al. (1999) developed two triple hybrids involving G. hirsutum and G. sturtianum using either $G$. thurberi Torado $(2 n=2 x=26$, genome D) or $G$. raimondii Ulbrich $(2 n=2 x=26$, genome D) as a bridge species. The backcrossing of the HRS hybrid [(G. hirsutum x G. raimondii) doubled x G. sturtianum] gave rise to $\mathrm{BC}_{1} ; \mathrm{BC}_{2}, \mathrm{BC}_{3}$ and $\mathrm{BC}_{2} \mathrm{~S}_{1}$ derivatives from seeds presenting very low densities of gossypol glands on their kernels.

Sunilkumar et al. (2006) recently reported another attempt to eliminate gossypol in seeds. Using RNAi techniques they produced F2 transgenic plants with $0.1 \mu \mathrm{g} / \mathrm{mg}$ seed gossypol, while maintaining gossypol and related terpenoids in the foliage and floral parts of the plant. This technique represents another possible way to modify seed gossypol, but further testing is still needed to confirm the expression in advanced generations of the terpenoid biosynthesis disruption in the seed.

The objective of this study was to evaluate the expression of the glandless-seed and glanded-plant trait in different genetic backgrounds involving $G$. hirsutum, three diploid species and eight different interspecific hybrids in order to better understand its determinism and assess the consequences of its introgression into $G$. hirsutum on TA content and composition in upland cotton seed and aerial organs.

\section{Materials and methods}

\section{Plant materials}

The seeds used in our investigations were produced by selfing 12 distinct genotypes (with different genetic 
backgrounds) maintained in the cotton collection of the Gembloux Agricultural University: one variety of $G$. hirsutum $\left[\left(2 n=4 x=52,2\left(\mathrm{~A}_{h} \mathrm{D}_{h}\right)\right]\right.$ (cv. STAM F) originating from West Africa; one accession of $G$. thurberi $(2 n$ $\left.=2 x=26,2 \mathrm{D}_{1}\right)$; one accession of $G$. raimondii $\left(2 n=2 x=26,2 \mathrm{D}_{5}\right)$; one accession of $G$. sturtianum $(2 n=2 x=$ $\left.26,2 \mathrm{C}_{1}\right)$; one synthetic allohexaploid : (G. hirsutum x G. sturtianum) doubled $\left(2\left[\mathrm{~A}_{h} \mathrm{D}_{h} \mathrm{C}_{1}\right]\right)$; three synthetic allotetraploids : (G. arboreum L. x G. sturtianum) doubled $\left(2\left[\mathrm{~A}_{2} \mathrm{C}_{1}\right]\right),(G$. thurberi x $G$. sturtianum) doubled $\left(2\left[\mathrm{D}_{1} \mathrm{C}_{1}\right]\right),\left(G\right.$. australe x $G$. davidsonii Kell.) doubled $\left(2\left[\mathrm{G}_{1} \mathrm{D}_{3-2}\right]\right)$; four plants obtained by backcrossing the HRS [(G. hirsutum x G. raimondii) doubled x G. sturtianum], $\left.\left[\mathrm{A}_{h} \mathrm{D}_{h} \mathrm{D}_{5} \mathrm{C}_{1}\right]\right)$ trispecific hybrid to G. hirsutum : HRS $\mathrm{BC}_{2} \mathrm{~S}_{1} / 09$, HRS $\mathrm{BC}_{2} / 14$, HRS $\mathrm{BC}_{3} / 09$ and $\mathrm{HRS} \mathrm{BC}_{3} / \mathrm{I} 3$. All these genotypes were characterized by very different levels of seed glands and the $\mathrm{BC}_{2} \mathrm{~S}_{1}$ and $\mathrm{BC}_{3}$ plants from the $\mathrm{HRS}$ trispecific hybrid were chosen for their ability to produce progenies segregating for this trait (Vroh Bi et al. 1999).

\section{Seed glands counting technique and surface evaluation}

Before being analyzed by HPLC, each seed was cut in two longitudinal sections after removal of the teguments in order to assess its total number of glands $(N)$ per section and its section area $\left(S\right.$ in $\left.\mathrm{mm}^{2}\right)$. These operations were carried out with a Nikon Eclipse E800 light and fluorescent microscope (Nikon, Tokyo, Japan) using a JVC-3-CCD color video camera (JVC, Tokyo, Japan) and the Archive Plus program from Sony (Sony Electronics, NJ, Park Ridge, USA) to capture and analyze the images.

\section{Evaluation of pigment gland density on aerial parts}

All plants were at least 1 year old and some of the arborescent species were older than 6 years. Since the studied genotypes were perennials with cyclical growth, 10 leaves and flower buds were selected from all of them at a similar growth stage. Number of pigment glands was evaluated five times on randomly selected squares of 25,8 , and $15 \mathrm{~mm}^{2}$, for leaves, calyx, and bract, respectively. These observations were carried out with the same scientific equipment used for gossypol gland counts on seeds. Simple correlation coefficients were calculated between the number of gossypol glands on leaves and flower buds and their total terpenoids aldehyde content (TTA).

\section{Assessment of seed by seed gossypol content}

The HPLC method optimized by Benbouza et al. (2002) was used to quantify the gossypol content on single seed samples. After being peeled, cut and weighed the seeds were ground in graduated $20 \mathrm{ml}$ tubes with 10-15 ml of liquid nitrogen and $0.5-1 \mathrm{ml}$ of glacial acetic acid. After the cryo-grinding, samples of seeds were hydrolyzed for $10 \mathrm{~min}$ in boiling water bath at $100^{\circ} \mathrm{C}$ with $4 \mathrm{ml}$ of glacial acetic acid. At the same time, two samples $(1-2 \mathrm{mg}) \mathrm{of}$ standard gossypol (Sigma ref. G-8761, St. Louis, MO, USA,) were treated similarly. The solutions were filtered through silanized glass wool into $20 \mathrm{ml}$ volumetric flasks. The residues were rinsed three times with 2-3 ml of a water/acetonitrile (50:50; V/V) mixture; the recovered solutions were diluted up to $20 \mathrm{ml}$ and homogenized carefully. The samples were then left at room temperature for $3 \mathrm{~h}$ before being filtered twice through a $0.20 \mu \mathrm{m}$ nylon membrane (MSI).

The samples were directly analyzed on a Merck Hitachi L 6200 chromatograph (Hitachi Ltd., Tokyo, Japan) equipped with a Merck Hitachi L 4000 UV. The chromatographic signals were integrated on a Hewlett Packard HP 1000 integrator (Hewlett Packard, USA). Other analytical conditions were fixed as follows:

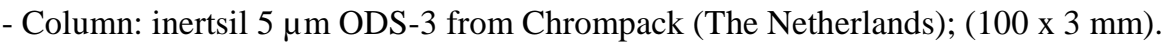

- Mobile phase: acetonitrile/water (acidified to $\mathrm{pH}=2.6$ with phosphoric acid) 88:12 (V/V) at flow rate of $0.5 \mathrm{ml}$ $\min ^{-1}$.

- UV detection at $272 \mathrm{~nm}$.

- Duplicates of 20- $\mu 1$ injections were made for all samples. The standard curve for gossypol was constructed from triplicate determinations each for gossypol quantities of $0.5,1,1.5$ and $2 \mathrm{mg}$.

\section{HPLC determination of foliar terpenoids aldehyde (TA)}

The HPLC procedure proposed by Stipanovic et al. (1988) was used for analyzes. The number of replications per organ analyzed varied from 1 to 10 according to the studied genotypes. Samples of dried leaves and flower buds were ground to a powder. Samples of $100 \mathrm{mg}$ were shaken $(225 \mathrm{rpm})$ for 30-min in capped $125 \mathrm{ml}$ Erlenmeyer 
flask with $15 \mathrm{ml}$ of glass beads, $10 \mathrm{ml}$ of 3:1 hexane:ethyl acetate (HEA), and $200 \mu \mathrm{l}$ of 10\% HCL (HOAc) (v/v) (for leaves) or $100 \mu \mathrm{l}$ of $10 \% \mathrm{HCL}$ (for flower buds). The solution was filtered through Whatman No. 1 filter paper supported on a fritted filter disk into a $50 \mathrm{ml}$ pear-shaped flask, and the beads and residue were rinsed three times with 2-3 $\mathrm{ml}$ of HEA. The solvent was evaporated under reduced pressure in a Büchi at $30^{\circ} \mathrm{C}$. The residue was resuspended with HEA $(4 \times 150 \mu 1)$, and each portion was transferred to a Maxi-clean silica cartridge $(600 \mathrm{mg})$ (Alltech). The cartridges were dried with a gentle stream of nitrogen, and then terpenoids were eluted with $5 \mathrm{ml}$ of isopropyl alcohol (IPA), acetoni-trile (ACN), water, and ethyl acetate (EtOAc) $(35: 21: 39: 5)(\mathrm{v} / \mathrm{v} / \mathrm{v} / \mathrm{v})$. The eluent was filtered through a $0.22 \mu \mathrm{m}$ nylon membrane (MSI), and a $1 \mathrm{ml}$ aliquot was transferred to a vial and sealed. The samples were analyzed as soon as possible after extraction because they were found to degrade with time.

Samples were analyzed on a Hewlett-Packard HP 1050 liquid chromatograph equipped with a diode array detector and a HP auto injector using a 125 x 4 mm 100 RP-18 (5 $\mu \mathrm{m})$ (Merck Lichrospher) column. A mobile phase of ethanol-methanol-isopropyl alcohol (IPA)-acetonitrile-(ACN) water-ethyl-dimethylformamide and phosphoric acid (16.7:4.6:12.1: 20.2:37.4:3.8:5.1:0.1) (v/v/v/v/v/v/v/v) was monitored at $272 \mathrm{~nm}$ at a flow rate of $1 \mathrm{ml} \mathrm{min}{ }^{-1}$. Duplicate $20 \mu \mathrm{l}$ injections were made for all samples. The analytical procedure was first optimized by changing the composition of the mobile phase and the elution temperature.

To be able to identify the peaks and to quantify the content of the gossypol and the heliocides in the extracts of leaves and flower buds, we used two pure standards: gossypol (SIGMA. Ref. G-8761) and hemigossypolonne (HGQ used only for identification, because of the very small quantity available). This standard was kindly provided by Dr. R. Stipanovic (USDA-ARS, College Station, USA). The identification of the heliocides $\left(\mathrm{H}_{1}\right.$ to $\mathrm{H}_{4}$ ) was performed on the basis of their relative retention data (gossypol as reference) and their UV spectrum. The calculation of the molar extinction coefficient $(\varepsilon)$ of the gossypol $(\varepsilon=518.54)$ in comparison with that of the heliocides found in the literature enabled us to quantify the identified heliocides as "gossypol equivalent" on the basis of a calibration curve established with a solution of gossypol.

\section{Results}

Seed gland density and quantification of seed gossypol content using the seed-by-seed HPLC method

Table 1 presents the results obtained from the observations made on the section of the seeds used to assess gossypol content with the seed-by-seed HPLC analysis method. For genotypes $\mathrm{BC}_{3} \mathrm{~S}_{1} / 09$ and $\mathrm{BC}_{2} \mathrm{~S}_{2} / 09$, we noted a reduction in the number of gossypol glands on the external tissues of the whole seed kernel, compared with the gossypol gland density observed in the parental species (G. hirsutum and G. raimondii) of the HRS trispecific hybrid.

The allotetraploids 2(G. thurberi x G. sturtianum), 2(G. arboreum x G. sturtianum), 2(G. australe x G. davidsonii), and the synthetic allohexaploid 2(G. hirsutum x G. sturtianum), which include all the chromosomes of the wild Australian species in their genome, also showed a significant reduction in the number of gossypol glands (Table 1).

The same tendency was observed for gossypol content quantification using the seed-by-seed HPLC analysis method (Table 1). All the analyzed hybrids showed a reduction in the seed gossypol content compared to their non-Australian parent. For the allotetraploids 2(G. thurberi x G. sturtianum), 2(G. arboreum x G. sturtianum), and the synthetic allohexaploid 2(G. hirsutum x G. sturtianum) the seed gossypol content was lower than $0.05 \%$. However, it was higher than this in the allotetraploid $2(G$. australe $\mathrm{x} G$. davidsonii). The best segregating genotypes of the trispecific hybrid $\mathrm{HRS}$, were the $\mathrm{BC}_{2} \mathrm{~S}_{1} / 09$ and $\mathrm{BC}_{3} / 09$ with $0.33 \%$ and $0.54 \%$, respectively. The correlation coefficient we calculated between the seed kernel gossypol content and the pigment gland density on the embryo was very high $(\mathrm{r}=0.906, P<0.001)$ indicating a coupling of these two parameters. 
Table 1. Results of gland counts and seed gossypol content (\%) assessment

\begin{tabular}{|c|c|c|c|}
\hline Genotypes & $n$ & $\begin{array}{l}\text { Average number of glands per } \\
\mathrm{mm}^{2}\end{array}$ & Gossypol content $(\%) \pm s d$ \\
\hline G. hirsutum cv. STAMF & 16 & 5.36 & $0.97 \pm 0.18$ \\
\hline G. raimondii & 6 & 9.73 & $2.33 \pm 0.34$ \\
\hline G. thurberi & 7 & 12.32 & $2.58 \pm 0.58$ \\
\hline G. sturtianum & 9 & 0 & 0 \\
\hline $2(G$. hirsutum x G. sturtianum $)$ & 7 & 1.76 & $0.03 \pm 0.01$ \\
\hline 2(G. thurberi x G. sturtianum) & 9 & 1.97 & $0.01 \pm 0.01$ \\
\hline $2(G$. arboreum $\times$ G. sturtianum $)$ & 6 & 1.57 & $0.01 \pm 0.00$ \\
\hline 2(G. australe х G. davidsonii) & 16 & 6.04 & $0.26 \pm 0.05$ \\
\hline $\mathrm{BC}_{2} \mathrm{~S}_{1} / 09$ & 16 & 2.77 & $0.33 \pm 0.22$ \\
\hline $\mathrm{BC}_{3} / 09$ & 19 & 3.28 & $0.54 \pm 0.19$ \\
\hline $\mathrm{BC}_{2} \mathrm{~S}_{1} / 14$ & 11 & 3.47 & $0.43 \pm 0.15$ \\
\hline $\mathrm{BC}_{3} / 13$ & 17 & 4.33 & $0.71 \pm 0.18$ \\
\hline
\end{tabular}

n, Seed number; sd, standard deviation

\section{Quantification of pigment gland density on aerial parts}

Table 2 presents the results obtained from gland counting observations made on the aerial parts. Pigment glands were present on all vegetative parts of the genotypes evaluated in this study. On leaves, the gossypol glands of G. raimondii had purple orange color. Those of $G$. hirsutum were smaller with black color and were denser than those of G. sturtianum, which had a black purple color. Evaluation of gland density highlighted a great variability between various plants and organs on the same plant, within cross ings and between different crossings. G. thurberi exhibited a high gland density on the leaves and calyces, while G. hirsutum had the lowest density on all evaluated organs, compared to the other species (Table 2).

Table 2. Results of gland counts on aerial organs

\begin{tabular}{|c|c|c|c|}
\hline \multirow[t]{2}{*}{ Genotypes } & \multicolumn{3}{|c|}{ Average number of gossypol glands } \\
\hline & Leaves $^{\mathrm{a}} \pm \mathrm{sd}$ & Bracts $^{b} \pm$ sd & Calyces $^{c} \pm s d$ \\
\hline G. hirsutum cv. STAM F & $58.4 \pm 0.8$ & $18.4 \pm 1.0$ & $15.5 \pm 1.3$ \\
\hline G. raimondii & $82.4 \pm 9.2$ & $56.6 \pm 2.6$ & $28.9 \pm 1.3$ \\
\hline G. thurberi & $224.8 \pm 5.1$ & $62.2 \pm 13.3$ & $57.9 \pm 2.1$ \\
\hline G. sturtianum & $63.4 \pm 6.6$ & $72.6 \pm 1.8$ & $29.8 \pm 1.6$ \\
\hline 2(G. hirsutum x G. sturtianum) & $54.1 \pm 7.9$ & $41.2 \pm 2.2$ & $18.7 \pm 0.8$ \\
\hline 2(G. thurberi x G. sturtianum) & $59.6 \pm 2.5$ & $84.8 \pm 1.3$ & $24.4 \pm 1.8$ \\
\hline 2(G. arboreum x G. sturtianum) & $27.8 \pm 3.5$ & $27.8 \pm 1.8$ & $13.1 \pm 1.0$ \\
\hline 2(G. australe x G. davidsonii) & $31.7 \pm 4.5$ & $14.1 \pm 0.4$ & $19.3 \pm 1.0$ \\
\hline $\mathrm{BC}_{2} \mathrm{~S}_{1} / 09$ & $74.6 \pm 5.2$ & $21.5 \pm 1.9$ & $19.7 \pm 1.3$ \\
\hline $\mathrm{BC}_{3} / 09$ & $39.7 \pm 2.2$ & $16.8 \pm 1.3$ & $10.7 \pm 1.9$ \\
\hline $\mathrm{BC}_{2} \mathrm{~S}_{1} / 14$ & $86.8 \pm 6.3$ & $20.6 \pm 3.2$ & $18.7 \pm 0.5$ \\
\hline $\mathrm{BC}_{3} / 13$ & $37.7 \pm 2.6$ & $13.1 \pm 1.5$ & $18.6 \pm 0.4$ \\
\hline
\end{tabular}

\footnotetext{
${ }^{a}$ Count of glands on $25 \mathrm{~mm}^{2}{ }^{b}$ Count of glands on $8 \mathrm{~mm}^{2}{ }^{c}$ Count of glands on of $15 \mathrm{~mm}^{2}$
} sd, Standard deviation 
The allotetraploid 2(G. thurberi x G. sturtianum) expressed the highest density on all evaluated organs, while 2(G. australe x G. sturtianum) had the lowest density on bracts and 2(G. arboreum x G. sturtianum) on calyces. Progenies of HRS notably $\mathrm{BC}_{2} \mathrm{~S}_{1} / 09$ and $\mathrm{BC}_{2} \mathrm{~S}_{1} / 14$ plants exhibited a high density of gossypol glands compared to the cultivated parent (G. hirsutum) of the triple hybrid.

\section{TA quantification on the aerial parts}

\section{Qualitative determination of the TA}

Separation of individual terpenoid aldehydes (TA) from each other is difficult considering that heliocides are isomers and structurally very similar. The TAs present in the leaves and flower buds have been identified by two distinct procedures:

(1) A direct method based on retention times (RT) measured by co-injection of the two available standards (HGQ or G; RT $=2.58$ - and 10.38-min, respectively). The RT of the standard gossypol and of the hemigossypolone were in close agreement with those obtained by Altaf et al. (1999): 2.51- and 10.37-min, respectively. To corroborate the identification, leave extracts and flower buds were spiked with a mixture of the $\mathrm{G}$ and HGQ standards. The increase in their corresponding peak areas confirmed the first identifications. Moreover, the recorded UV spectrum fitted exactly with those of pure references. (2) The heliocides $\mathrm{H}_{1}, \mathrm{H}_{2}, \mathrm{H}_{3}$ and $\mathrm{H}_{4}$, were identified by calculation of relative times retention (RT) with the gossypol as reference. The values obtained were in perfect agreement with those of Altaf et al. (1999).

\section{Quantitative determination of the TA}

The quantification of the TAs [HGQ, $\mathrm{G}$ and heliocides $\left(\mathrm{H}_{1}, \mathrm{H}_{2}, \mathrm{H}_{3}\right.$ and $\left.\mathrm{H}_{4}\right)$ ] was conducted by using a calibration curve established with increasing amounts of $\mathrm{G}$. We then calculated the molar extinction coefficient $(\varepsilon)$ of $\mathrm{G}$ in chloroform which was compared with those of other heliocide published values (Stipanovic et al. 1978a, b). We found that $\varepsilon$ values for the various heliocides were of the same order of magnitude. $\varepsilon \mathrm{G}=31784 ; \varepsilon \mathrm{H}_{1}=31200$; $\varepsilon \mathrm{H}_{4}=28500 ; \varepsilon \mathrm{H}_{3}=37700$. For $\mathrm{H}_{2}$ we hypothesized an $\varepsilon$ value close to that of $\mathrm{H}_{3}$ because the structures of these two molecules are very similar.

The first modification we made to the method was the composition of the mobile phase. We obtained acceptable separation of the peaks with $80 \%$ efhanol-methanol-isopropyl alcohol (IPA)-acetonitrile-(ACN) water-ethylDimethylformamide and phosphoric acid (16.7:4.6:12.1:20.2:37.4:3.8:5.1:0.1) and 20\% acetonitrile. A temperature ranging from 35 to $55^{\circ} \mathrm{C}$ led to a drastic decrease in column selectivity. Therefore, the elution temperature was fixed at $25^{\circ} \mathrm{C}$. Under this condition, the run time for one analysis was $20 \mathrm{~min}$.

\section{Quantification of the TA content in leaves}

Table 3 shows the results obtained by HPLC analysis of TAs in leaves for all evaluated genotypes. The results indicate very high qualitative and quantitative variability between the investigated genotypes. For G. hirsutum all investigated TAs were present (Fig. 1). The heliocide $\mathrm{H}_{2}$ was the predominant TA and $\mathrm{G}$ was relatively low in quantity. G. raimondii possessed the unique TA, the raimondal (95\%) (Table 3) and a very low content of G (Fig. 2), while G. thurberi was notable for its high concentration of TTA in which G was the dominant contributor $(42.1 \%)$, HGQ was the lower one $(1.4 \%)$ and the heliocides $\left(\mathrm{H}_{1}\right.$ to $\left.\mathrm{H}_{4}\right)$ were not detected. G. sturtianum possessed HGQ, $\mathrm{H}_{1}$ and $\mathrm{H}_{2}$ TAs in moderate quantities, while $\mathrm{H}_{3}$ was not detected and $\mathrm{G}$ occurred as a minor constituent.

All allotetraploids had moderate concentrations of TTA but the tetraploid hybrid 2(G. australe x G. davidsonii) showed a low quantity of TTA. HGQ and G were present in all allotetraploids but heliocides presented qualitative differences (Table 3). Heliocides $\mathrm{H}_{1} ; \mathrm{H}_{3}$ and $\mathrm{H}_{4}$ were not detected in the allohexaploid 2(G. hirsutum x G. sturtianum), while HGQ had the highest percentage and $\mathrm{G}$ the lowest one.

Progenies of the trispecific hybrid HRS exhibited the lowest concentrations of TTA compared to the other analyzed genotypes. TAs were not detected in $\mathrm{BC} 3 / \mathrm{I} 3$ leaf extracts. HGQ and $\mathrm{G}$ were the unique TAs present in leaves of $\mathrm{BC}_{3} / 09, \mathrm{~B}_{2} \mathrm{C}_{1} / 09$ and $\mathrm{BC}_{2} \mathrm{~S}_{1} / 14$ plants; while heliocides $\mathrm{H}_{1}$ to $\mathrm{H}_{4}$ were not detected in all progenies of the trispecific hybrid HRS. In line with Altman et al. (1991) and Altaf et al. (1999), we observed the presence of several unknown compounds. Our results show that for G. thurberi, G. sturtianum, allotetraploids and the allohexaploid, unknown compounds represent more than half of the six common TA content. Some of these 
compounds are likely terpenoid. Further analyzes should be undertaken to characterize these compounds. The same observation can be made for the backcross plants; however, the TTA contents were lower.

Table 3. Percentages and concentrations of TA present in leaves

\begin{tabular}{|c|c|c|c|c|c|c|c|c|c|}
\hline \multirow[t]{2}{*}{ Genotypes } & \multirow[t]{2}{*}{$a$} & \multicolumn{2}{|c|}{ Mean (\%) } & \multirow[t]{2}{*}{$\mathbf{H}_{1}$} & \multirow[t]{2}{*}{$\mathbf{H}_{2}$} & \multirow[t]{2}{*}{$\mathbf{H}_{3}$} & \multirow[t]{2}{*}{$\mathbf{H}_{4}$} & \multirow[t]{2}{*}{ TTAI (\%) } & \multirow[t]{2}{*}{ TTA $(\mu \mathrm{g} / \mathrm{g})$} \\
\hline & & HGQ & $G$ & & & & & & \\
\hline G. hirsutum cv. STAM F & 10 & 1.6 & 1.3 & 32.4 & 41 & 13.6 & 9.6 & 99.5 & $188.8 \pm 27.4$ \\
\hline $\begin{array}{l}\text { G. raimondii }(\mathrm{R}=747.9) \\
(94.9 \%)\end{array}$ & 6 & - & 0.6 & - & & - & - & 95.5 & $790.8 \pm 172.4$ \\
\hline G. thurberi & 4 & 1.4 & 42.1 & - & - & - & - & 43.5 & $1135.3 \pm 131.4$ \\
\hline G. sturtianum & 5 & 8.8 & 0.9 & 8.8 & 8.2 & - & 4 & 30.7 & $499.2 \pm 73.5$ \\
\hline $\begin{array}{l}2(G . \text { hirsutum x } G . \\
\text { sturtianum })\end{array}$ & 4 & 14.5 & 0.8 & - & 8.5 & - & - & 23 & $582 \pm 53.9$ \\
\hline 2(G. thurber x G. sturtianum) & $3 / 7$ & 0.9 & 15.4 & - & - & - & - & 16.3 & $191.9 \pm 11.9$ \\
\hline $\begin{array}{l}\text { 2(G. arboreum } \times G . \\
\text { sturtianum) }\end{array}$ & 4 & 6.3 & 0.6 & - & 11.3 & - & - & 18.2 & $303.8 \pm 27.4$ \\
\hline 2(G. australe x G. davidsonii) & 4 & 2.8 & 2.5 & - & - & 2.3 & 4.3 & 11.9 & $34.9 \pm 0.1$ \\
\hline $\mathrm{BC}_{2} \mathrm{~S}_{1} / 09$ & 4 & 9.5 & 16.3 & - & - & - & - & 25.8 & $7.3 \pm 0.4$ \\
\hline BC3/09 & 4 & 22.8 & 29.2 & - & - & - & - & 52 & $4.3 \pm 0.3$ \\
\hline $\mathrm{BC}_{2} \mathrm{~S}_{1} / 14$ & 4 & 28.2 & 34.1 & - & - & - & - & 62.3 & $3.9 \pm 0.1$ \\
\hline $\mathrm{BC} 3 / 13$ & 4 & - & - & - & - & - & - & & - \\
\hline
\end{tabular}

Fig. 1: Chromatogram of the G. hirsutum cv. STAM F leaf extract. Legend: HGQ-hemigossypolone G-gossypol; heliocides- $H_{1}$ to $H_{4}$

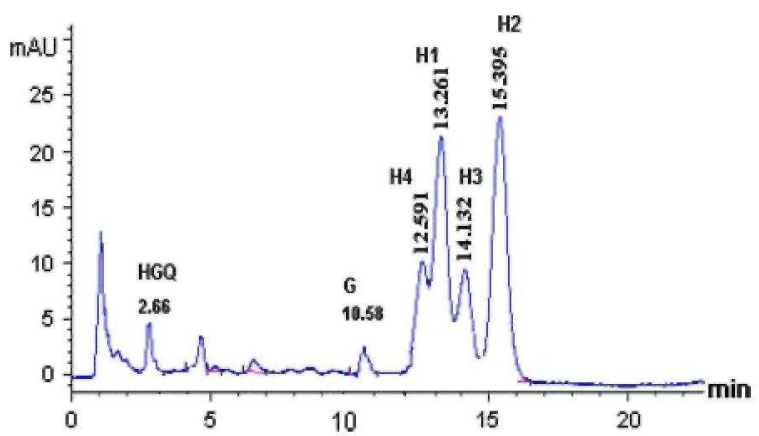

Fig. 2: Chromatogram of G. raimondii leaf extract. Legend: G—gossypol; $R$-raimondal

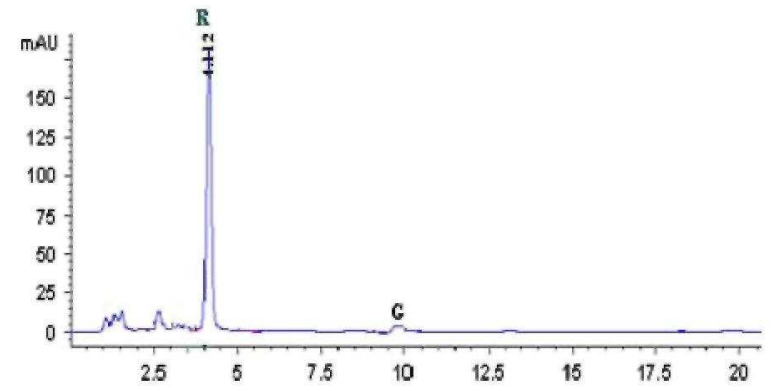

Quantification of the TA content in flower buds

The total concentration of TA (TTA) and the percentage of HGQ, G and heliocides $\left(\mathrm{H}_{1}\right.$ to $\left.\mathrm{H}_{4}\right)$ in flower buds of 
each genotype are given in Table 4. G was the major constituent of all genotypes, except for G. sturtianum with $3.58 \%$ and the allotetraploid 2(G. arboreum x G. sturtianum) with $2.5 \%$. G. hirsutum possessed all the six TTA (Fig. 3) in moderate concentration, while heliocides were not detected in G. sturtianum which had the lowest content of TTA. Species of genome (D) G. thurberi (Fig. 4) and G. raimondii (Table 4) possessed a high concentration of TTA, but heliocides $\left(\mathrm{H}_{1}\right.$ to $\left.\mathrm{H}_{4}\right)$ were not detected. Allotetraploids showed high qualitative and quantitative differences (Table 4) and those crossed with (D) genome species had the highest concentration of TTA. The allohexaploid 2(G. arboreum x G. sturtianum) had a moderate percentage of all the six TA with a predominance of $\mathrm{H}_{1}$ HRS derivatives possessed moderate percentage of heliocides $\left(\mathrm{H}_{1}\right.$ to $\left.\mathrm{H}_{4}\right)$; $\mathrm{G}$ was the most prevalent TA compound and the concentration of TTA was similar to the cultivated parent G. hirsutum. The $\mathrm{BC}_{2} \mathrm{~S}_{1} / 09, \mathrm{BC}_{2} \mathrm{~S}_{1} / 14, \mathrm{BC}_{3} / 09$ and $\mathrm{BC}_{3} / 13$ plants contained a high proportion of $\mathrm{G}$ with, respectively, a mean rate of $40.4 \%$ and $37.8 \%$. The results given in Table 4 also indicate that unknown compounds represented a high proportion of TTA compared to the six common compounds (G, HGQ and heliocides $\left.\mathrm{H}_{1}-\mathrm{H}_{4}\right)$ in all genotypes (Fig. 4).

Establishment of a relationship between the density of pigment glands and the content of TAs in aerial parts

In order to determine whether the chemical differences corresponded to a change in the number of pigment glands on the evaluated organs, Pearson correlation coefficients were calculated for several variables. Significant positive correlation values were obtained between the content of TTA and the number of pigment glands in leaves $(r=0.727, P=0.08)$, calyces $(r=0.634, P=0.027)$ and bracts $(r=0.656, P=0.021)$.

Table 4. Percentages and concentrations of TA present in flower buds

\begin{tabular}{|c|c|c|c|c|c|c|c|c|c|}
\hline \multirow[t]{2}{*}{ Genotypes } & \multirow[t]{2}{*}{$a$} & \multicolumn{2}{|c|}{ Mean (\%) } & \multirow[t]{2}{*}{$\mathbf{H}_{1}$} & \multirow[t]{2}{*}{$\mathbf{H}_{2}$} & \multirow[t]{2}{*}{$\mathbf{H}_{3}$} & \multirow[t]{2}{*}{$\mathbf{H}_{4}$} & \multirow[t]{2}{*}{ TTAI (\%) } & \multirow{2}{*}{$\begin{array}{l}\text { TTA }(\mu g / g) \\
(\text { sd) }\end{array}$} \\
\hline & & HGQ & $\mathrm{G}$ & & & & & & \\
\hline G. hirsutum cv. STAM F & 6 & 9.9 & 16.7 & 10 & 17.2 & 6.8 & 8 & 68.6 & $369.8 \pm 54.7$ \\
\hline G. raimondii & 3 & 6.7 & 65.1 & - & - & - & - & 71.8 & $1622.1 \pm 72$ \\
\hline G. thurberi & 3 & 0.6 & 66.6 & - & - & - & - & 67.2 & $2011.8 \pm 132.3$ \\
\hline G. sturtianum & 3 & 4.78 & 3.58 & - & - & - & - & 8.28 & $264 \pm 23.3$ \\
\hline $\begin{array}{l}\text { 2(G. hirsutum x } G . \\
\text { sturtianum) }\end{array}$ & 2 & 11.9 & 13.9 & 4.3 & - & 8.3 & 10.2 & 47.3 & $641.6 \pm 4.6$ \\
\hline $\begin{array}{l}2(G . \text { thurberi x } G . \\
\text { sturtianum })\end{array}$ & 2 & 3.1 & 77.4 & - & - & - & - & 80.5 & $2041.5 \pm 254.2$ \\
\hline $\begin{array}{l}\text { 2(G. arboreum x } G . \\
\text { sturtianum) }\end{array}$ & 4 & 6.1 & 2.5 & 15.6 & 3.7 & 8 & 6.9 & 42.8 & $135.8 \pm 7.3$ \\
\hline $\begin{array}{l}\text { 2(G. australe x } G . \\
\text { davidsonii) }\end{array}$ & 3 & 7 & 13.3 & 37.6 & - & - & - & 54.9 & $1169.6 \pm 64.3$ \\
\hline $\mathrm{BC}_{2} \mathrm{~S}_{1} / 09$ & 5 & 6.6 & 40.3 & 5.5 & 6.2 & 1.9 & 3.9 & 71 & $393.4 \pm 48.1$ \\
\hline $\mathrm{BC}_{3} / 09$ & 1 & 0.9 & 39.6 & 4.9 & 5.7 & 1.4 & 3.8 & 56.3 & 419.7 \\
\hline $\mathrm{BC}_{2} \mathrm{~S}_{1} / 14$ & 4 & 3 & 40.5 & 3.1 & 3.1 & 1.5 & 1.8 & 53 & $375.2 \pm 13.6$ \\
\hline $\mathrm{BC}_{3} / 13$ & 3 & 3.8 & 36 & 1.8 & 3.5 & 2.4 & 3.8 & 51.3 & $310.1 \pm 32.8$ \\
\hline
\end{tabular}

a, Number of repetition; -, not detected; TTA, total content terpenoid aldehydes; TTAI, total terpenoid aldehydes indentified; G, gossypol; $H G Q$, hemigossypolone; $\mathrm{H}_{1}, \mathrm{H}_{2}, \mathrm{H}_{3}, \mathrm{H}_{4}$, heliocides; sd, standard deviation

$\%$ was calculated as a function of TTA

Fig. 3: Chromatogram of G. hirsutum cv. STAM F flower bud extract. Legend: HGQ-hemigossypolone; $G$-gossypol; heliocides- $\mathrm{H}_{1}$ to $\mathrm{H}_{4}$

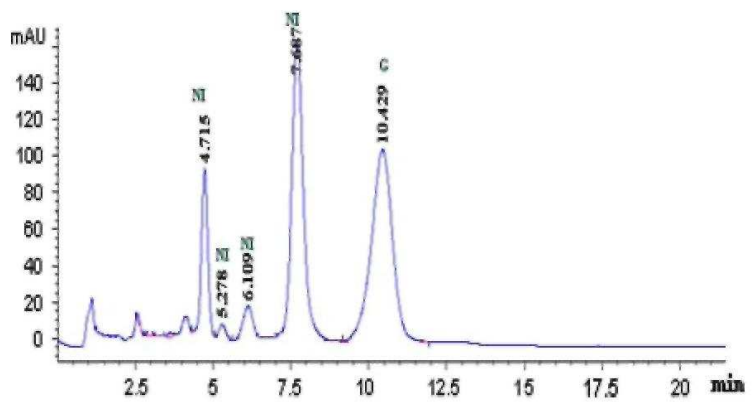


Fig. 4. Chromatogram of G. thurberi leaf extract. Legend: G-gossypol

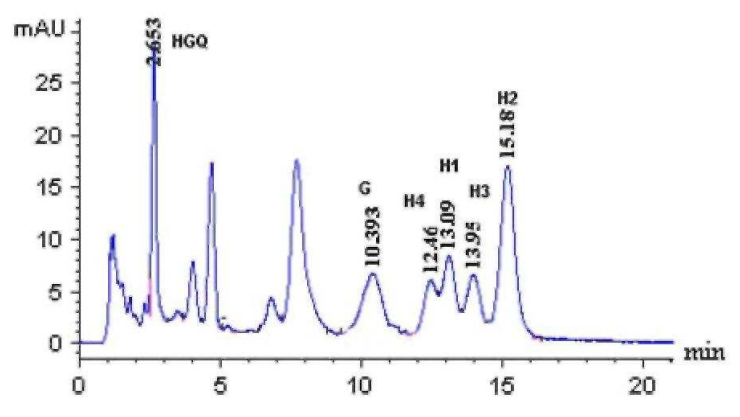

\section{Discussion}

A high level of variability was observed for the chemical composition and pigment gland density in all the organs of the genotypes investigated. Several authors have highlighted the great qualitative and quantitative variation of TA content in different cotton species (Altman et al. 1990, 1991; Altaf et al. 1999).

In this study, all the interpecific hybrids [2(G. thurberi x G. sturtianum), 2(G. arboreum x G. sturtianum), 2(G. australe x G. davidsonii), and 2(G. hirsutum x G. sturtianum)], and the progenies of the HRS hybrid including the genome, $\mathrm{C}$ or $\mathrm{G}$, of the Australian wild diploid species produced seeds with reduced number of gossypol glands and showed a drastic diminution of gossypol seed content compared to their non-Australian parent, while all the vegetative parts of the plants were glanded. Which indicates a partial expression of the glandless-seed and glanded plant trait in all evaluated genotypes. According to the U.S. Food and Drug Administration (FDA), free gossypol content of edible cotton products should not exceed $450 \mathrm{ppm}$. The United Nation Food and Agriculture and World Health Organization (FAO/WHO) set maximum value of 600 ppm (Lusas and Jividin 1987).

Content of TA vary among accessions of the same species and also by stage of plant growth, the environmental conditions (Stipanovic et al. 1988; Altman et al. 1989), and the organ type and size (Hedin et al. 1991). The TTA content we measured for the three diploid species investigated and G. hirsutum are three- to ten-fold lower than the data obtained by Altaf et al. (1999) for the same species.

Presence of very low content of TTA in the leaves of the HRS backcross derivatives was due to an absence of the heliocides $\mathrm{H}_{1}-\mathrm{H}_{4}$ in their organs that was not compensated by a sufficient increase in the quantity of unknown TA compounds. This reduction of the TTA content occurred despite a high density of pigment glands on leaves, notably on BC2S1/09 and BC2S1/14 plants, compared to those observed in the cultivated parent G. hirsutum. On the contrary, for flower buds of the same genotypes, we observed that a high level of gland density on bracts and calyces was associated with a relatively high concentration of TTA, compared to the cultivated parent.

Altman et al. (1990) obtained a significant reduction in HGQ and heliocides $\mathrm{H}_{1}-\mathrm{H}_{4}$ content in the hybrids resulting from interspecific crossing between $G$. raimondii and three cultivars of G. hirsutum, compared to the contents of the same compounds found in the cultivated parent. This reduction was associated with an increase in the gland density on the leaves of the hybrids.

The relatively high value of the linear correlation coefficient calculated between the number of glands found on the leaves and the content of the TTA $(r=0.725, P=0.01)$ considering all the investigated genotypes is, however, not in agreement with this observation. This level of correlation indicates a coupling of leaf-tissue TA content and glandulosity (Lee 1973; McAuslane and Alborn 1998).

Pauly (1979) indicates that it is difficult to determine exactly the function of the alleles controlling the glandular character in the production and/or the storage of the terpenoid, and he stressed that more than one gene was responsible for the production of some terpenoidic compounds.

Brubaker et al. (1996), in a study on the presence of terpenoids and gossypol glands in seeds of the Australian species, proposed that the two mechanisms could be independent. Benedict et al. (2004) discovered a somaclonal variant where a decrease in terpenoid products in seed and leaf tissues was not associated with a reduction in number or size of glands. 
In the flower buds the content of TTA was raised, in particular that of the gossypol, compared with those found in the two parental species (G. hirsutum and G. sturtianum) of HRS hybrid.

Altman et al. (1990), indicated that the concentration of HGQ and heliocides $\left(\mathrm{H}_{1}-\mathrm{H}_{4}\right)$ were weak in the hybrids compared to those found in G. hirsutum, whereas the content of gossypol was higher in the hybrids.

This can indicate segregation or a repression of expression of various genes controlling the biosynthesis of the terpenoids. Expression of two dominant alleles $\mathrm{GL}_{2}$ and $\mathrm{GL}_{3}$ is under the influence of the genetic background in which they act. This genetic background acts by repressor or modifying genes. The transfer of alleles between species can lead to a breakup of the original system (alleles of modifying genes) and result in a reduction of the efficiency of the alleles in the genetic background (Pauly 1979). The genetic control of the glandless-seed and glanded plant trait in Australian wild species such as G. sturtianum remains unknown.

The content of TA measured, in this study, were generally lower than the literature data. This could be attributed to the cultivation conditions, the growth stage of sampling and the specificity of the tested genotypes. Altaf et al. (1999) observed a very high variability in leaf TTA content among seven G. laxum accessions cultivated in the same environment. The results showed the occurrence of unknown compounds in a relatively high proportion for several genotypes. Some of these unknown compounds could confer a specific resistance to cotton pests. Their terp-enoic nature has not been established. Therefore, additional investigation should be undertaken in order to test this hypothesis. This study demonstrates that selection must be conscientious in order to maximize expression of the TAs in progenies.

\section{Conclusion}

Reductions of pigment gland density on the seed kernel as well as the cottonseed gossypol content noted in the allotetraploid and allohexaploid hybrids involving G. sturtianum and G. australe, indicate a partial expression of the repressive mechanism(s) that control the gene(s) involved in pigment gland formation and gossypol synthesis. The effectiveness of the repression mechanism varied depending on the genome that was associated with the Australian species. The seed gossypol content was much lower for 2(G. thurberi x G. sturtianum), 2(G. arboreum x G. sturtianum) and 2(G. hirsutum x G. sturtianum) hybrids than for the allotetraploid 2(G. australe $\mathrm{x}$ G. davidsonii).

A close coupling between the glandulosity of the embryo and its gossypol content was observed for the investigated genotypes. The same general trend was observed between the pigment gland density in the aerial tissues and the TTA content. Exceptions to this correlation were, however, noted for the backcross derivatives of HRS triple hybrid. In these genotypes, a decrease in the TTA content was observed despite the maintenance of a high number of pigment glands per leaf and flower bud unit area. This observation was in accordance with those of others (Altman et al. 1990; Brubaker et al. 1996). It indicates that separation between pigment gland morphogenesis and terpenoid synthesis mechanisms was possible in particular situations.

The results obtained in this work show that the exploitation of Australian wild species such as G. sturtianum and G. australe offers interesting possibilities for the introgression of the low-gossypol seed character into cotton commercial varieties. A cotton plant having the high glanding (HG) character and expressing low-gossypol seed would have economic importance. The studied genotypes express a large variability for gland densities in seeds and in the vegetative parts which can be exploited by breeders. Moreover, HPLC analysis reveals quantity and quality diversity of TA present in leaves and flower buds among different genetic backgrounds which supports the evidence for quantitative control of TA synthesis. Thus, terpenoid introgression for profile shifts is possible but will require careful progeny selection to maximize expression.

\section{Acknowledgments}

The PhD scholarship for Halima Ben-bouza was provided by the Belgian General Direction of International Cooperation (DGCI). This work was supported by the Belgian "Fonds de la Recherche Fondamentale et Collective". 
Published in: Euphytica (2009), vol. 165, iss.2, pp. 211-221

Status: Postprint (Author's version)

\section{References}

Ahoton L, Lacape JM, Baudoin JP, Mergeai G (2003) Introduction of Australian diploid cotton genetic variation into Upland cotton. Crop Sci 43:1999-2005

Altaf KM, Stewart J, Murphy JB (1999) Plant genetic resources. Evaluation of the Gossypium gene pool for foliar terpenoid aldehydes. Crop Sci 39:253-258

Altman DW, Stelly DM, Kohel RJ (1987) Introgression of the glanded-plant and glandless-seed trait from Gossypium sturtianum Willis into cultivated upland cotton using ovule culture. Crop Sci 27:880-884

Altman DW, Stipanovic RD, Benedict JH (1989) Terpenoid aldehydes in upland cottons. II. Genotype-environment interactions. Crop Sci 29:1451-1456

Altman DW, Stipanovic RD, Bell AA (1990) Terpenoids in foliar pigment glands of A, D, and AD genome cottons: introgression potential for pest resistance. J Hered 81:447-454

Altman DW, Stipanovic RD, Bell AA (1991) Terpenoids of Asiatic and Western Hemisphere diploid and tetraploid cottons. In: Herber DJ, Richter DA (eds) Proceedings of beltwide cotton conference national cotton council, Memphis, TN, pp 534-437

Benbouza H, Lognay G, Palm R, Baudoin JP, Mergeai G (2002) Development of a visual method to quantify the gossypol content in cotton seeds. Crop Sci 42:1937-1942

Benbouza H, Diouf T, Baudoin JP, Mergeai G (2007) Preferential transmission of Gossypium sturtianum chromosome fragments in the progeny of [2(G. hirsutum x G. raimondii) x G. sturtianum] trispecific hybrid. In: Proceedings of WCRC, vol 4, September Lubbock, USA, pp $10-14$

Benedict CR, Martin GS, Liu J, Puckhaber L, Magill CW (2004) Terpenoid aldehyde formation and lysigenous gland storage sites in cotton: variant with mature glands but suppressed levels of terpenoid aldehydes. Phytochemistry 65:1351-1359

Brubaker CL, Benson CG, Miller C, Leach ND (1996) Occurrence of terpenoid aldehydes and lysigenous cavities in the "glandless" seeds of Australian Gossypium species. Aust J Bot 44:601-612

Dilday RH (1986) Development of a cotton plant with glandless seeds, and glanded foliage and fruiting forms. Crop Sci 26:639-641

Fryxell PA (1965) A revision of the Australian species of Gossypium with observations on the occurrence of Thespesia in Australia (Malvaceae). Aust J Bot 13:71-102

Hedin PA, Parrott WL, Jenkins JN (1991) Effects of cotton plant allelochemicals and nutrients on behavior and development of Tobacco Budworm. J Chem Ecol 17:1107-1121

Koto E (1989) Tentative de transfert du caractère "retard à la morphogenèse des glandes à gossypol" I. caractéristiques des hexaploïdes $G$. hirsutum x G. sturtianum et G. hirsutum x G. australe. In: M I. (ed) 1ère Conférence de la recherche cotonnière africaine, Lomé, Togo, pp $167-173$

Lee JA (1965) The genomic allocation of the principal foliar-gland loci in Gossypium hirsutum and Gossypium. Evol 19:182-188

Lee JA (1973) The inheritance of gossypol level in Gossypium II: inheritance of seed gossypol in two strains of cultivated Gossypium barbadense L. Genetics 75:259-264

Lusas EW, Jividin GM (1987) Glandless cottonseed: a review of the first 25 years of processing and utilization research. J Am Oil Chem 64:839-854

McCarty JC, Hedin PA, Stipanovic RD (1996) Cotton Gossypium spp. plant gossypol contents of selected $\mathrm{Gl}_{2}$ and $\mathrm{Gl}_{3}$ alleles. J Agric Food Chem 44:613-616

McAuslane HJ, Alborn HT (1998) Systemic induction of allochemicals in glanded and glandless isogenic cotton by Spodoptera exigua feeding. J Chem Ecol 24:399-416

McMichael SC (1954) Glandless boll in Upland cotton and its use in the study of natural crossing. Agron J 46:527-528

Muramoto H (1969) Hexaploid cotton: some plant and fiber properties. Crop Sci 9:27-29

Pauly G (1979) Les glandes à pigments du cotonnier: aspects génétique et sélection des variétés glandless et high gossypol. Cotton Fibres Trop 34:379-402

Rooney W, Stelly D, Altman D (1991) Identification of four Gossypium sturtianum monosomic alien addition derivatives from backcrossing program with G. hirsutum. Crop Sci 31:337-341 
Published in: Euphytica (2009), vol. 165, iss.2, pp. 211-221

Status: Postprint (Author's version)

Shuijin Z, Biling L (1993) Studies of introgression of the "glandless seeds-glanded plant" trait from Gossypium bickii into cultivated upland cotton (G. hirsutum). Cotton Fibres Trop 48:195-199

Stipanovic R, Bell A, O'Brien D, Lukfahr M (1978a) Heliocide H3 an insecticidal terpenoid from Gossypium hirsutum. Phytochemistry 17:151-152

Stipanovic R, Bell A, O'Brien D, Lukfahr M (1978b) Heliocide H1. A new insecticidal C25 terpenoid from cotton (Gossypium hirsutum). J Agric Food Chem 28:115-118

Stipanovic RD, Altman DW, Begin DL, Greenblatt GA, Benedict JH (1988) Terpenoid aldehydes in upland cottons: analysis by aniline and HPLC methods. J Agric Food Chem 36:509-515

Sunilkumar G, Campbell LM, Puckhaber L, Stipanovic RD, Rathore KS (2006) Engineering cottonseed for use in human nutrition by tissuespecific reduction of toxic gossypol. Proc Natl Acad Sci 103:18054-18059

Vroh Bi I, Baudoin JP, Hau B, Mergeai G (1999) Development of high-gossypol cotton plants with low-gossypol seeds using trispecies bridge crosses and in vitro culture of seed embryos. Euphytica 106:243-251 